\title{
Data sets on pensions and health: Data collection and sharing for policy design
}

\author{
Jinkook Lee \\ RAND Corporation, United States
}

\begin{abstract}
A growing number of countries are developing or reforming pension and health policies in response to population ageing and to enhance the welfare of their citizens. The adoption of different policies by different countries has resulted in several natural experiments. These offer unusual opportunities to examine the effects of varying policies on health and retirement, individual and family behaviour, and well-being. Realizing these opportunities requires harmonized data-collection efforts. An increasing number of countries have agreed to provide data harmonized with the Health and Retirement Study in the United States. This article discusses these data sets, including their key parameters of pension and health status, research designs, samples, and response rates. It also discusses the opportunities they offer for cross-national studies and their implications for policy evaluation and development.
\end{abstract}

\section{Keywords}

data analysis; comparison; old age risk; health status; quality of life; social policy; demographic aspect; international

\section{Introduction}

Population ageing is occurring in nearly all regions of the world. This is leading to increased public outlays for old-age pension payments and health care expenditures, especially where pensions are financed on a pay-as-you-go basis and acute and long-term care services are widely available (Kinsella and He, 2009). Increased public outlays for old-age pensions raise issues of generational equity as well as concerns about pension system solvency. In many developed and developing countries, pension reform has become and continues to be a high priority, although its pace varies by country. The adoption of different policies by different countries has resulted in several natural experiments, offering unusual opportunities for governments to learn from experiences elsewhere.

Policy analysts have been long aware of the value of comparative analyses and the opportunities they offer for learning lessons from policies adopted elsewhere (Casey, 2009). Most analyses examine policy differences between countries or the effectiveness of a policy within a country. The ultimate goal of such analysis is to predict the effectiveness of a policy 
adopted in one country when introduced in another. Comparable micro-data across countries are required for such analysis. If a number of countries were to develop and share comparable data in a common research framework, major scientific and policy gains would be possible. The scientific promises of such comparative research are well known (National Research Council, 2001), but the lack of comparable micro-data across countries holds back such work.

Fortunately, an increasing number of countries are providing harmonized data to better understand population ageing and the multifaceted lives of older individuals and their families (Lee, 2007a). These harmonized international data sets on ageing are rooted in the Health and Retirement Study (HRS) in the United States and include both developed and developing countries. The HRS "family" of surveys includes the Mexican Health and Aging Study (MHAS), the English Longitudinal Study of Ageing (ELSA), the Survey of Health, Ageing, and Retirement in Europe (SHARE), the Korean Longitudinal Study of Ageing (KLoSA), the Japanese Study on Aging and Retirement (J-STAR), the Chinese Health and Retirement Longitudinal Study (CHARLS), the Irish Longitudinal study on Ageing (TILDA), and the Longitudinal Ageing Study in India (LASI). This article introduces these harmonized data sets, describes their key parameters of pension and health, and discusses the opportunities they afford for cross-national studies to help improve policy.

\section{HRS and its sister surveys around the world}

\section{Health and Retirement Study (HRS)}

HRS is a multipurpose, longitudinal household survey, representing the United States' population aged 50 years or older. ${ }^{1}$ The initial HRS was designed as a longitudinal study, first conducted in 1992, of a sample of persons born between 1931 and 1941, representing the community-residing ${ }^{2}$ population of the United States between 51 and 61 years of age at the time of first interview. Subsequent biennial waves retained respondents who later entered an institution. The sample included age-eligible persons and their spouses or partners (regardless of age). In 1993, a companion study of the Asset and Health Dynamics of the Oldest Old (AHEAD) was launched, representing cohorts born before 1924, or those who were at least aged 70 when first interviewed. The AHEAD cohort and their spouses or partners were re-interviewed in 1995. In 1998, the HRS and AHEAD cohorts were combined, and two new six-year cohorts, representing persons born from 1924 to 1930 and those born from 1942 to 1947, entered the study. The entire sample represented the United States' population older than age 50 in 1998. HRS also introduced a steady-state design that can simultaneously support continuous cross-sectional descriptions of the United States' population older than age 55, longitudinal studies of a given cohort over a substantial period of time, and research on cross-cohort trends. In 2004, the HRS added respondents born from 1948 to 1953; in 2010, it will add respondents born from 1954 to 1959.

\footnotetext{
${ }^{1}$ See <http://hrsonline.isr.umich.edu/>.

${ }^{2}$ The community-residing population excludes all those under formally-authorized supervised care or custody in institutions (i.e. the institutionalized population).
} 
HRS was designed by an interdisciplinary group of investigators at the University of Michigan and other universities and research institutions across the United States with expertise in economics, demography, medicine, psychology, sociology, and survey methods. It has differed slightly across years, but has always included information on physical, emotional, and cognitive health characteristics. It has self-reported data on a range of chronic health conditions; on socioeconomic status, including high-quality income and wealth modules; on work, retirement and pensions; on demographic characteristics of respondents and their family members; on family transfers of money and time in the form of care giving; on formal and informal social network and activities; and on expectations.

The goal of the HRS is to produce public-use data for researchers addressing the scientific and policy challenges posed by an ageing population (Willis, 2006). Its influence is indicated by its 9,937 registered users and the 18,276 publications it has generated through March 2009. Such remarkable scientific success, along with rising concerns over global ageing, has generated substantial interest elsewhere in similar data. Table 1 summarizes key characteristics of these surveys, which are described in more detail below. An annex to this article also describes four additional, related surveys worth noting for the study of ageing populations: the Indonesian Family Life Survey, the World Health Organization (WHO) Study on Global AGEing and Adult Health (SAGE), the Costa Rican Longevity and Healthy Aging Study, and the Canadian Longitudinal Study of Aging.

\section{Mexican Health and Aging Study (MHAS)}

MHAS is a nationally-representative panel study of Mexicans aged 50 or older and their spouses/partners regardless of their age. ${ }^{3}$ MHAS respondents were identified in conjunction with the 2000 National Employment Survey (Encuesta Nacional de Empleo - ENE). Among the age-qualifying ENE sample, 15,186 individuals from 9,862 households participated in the first wave in 2001. A second wave of interviews with surviving respondents and next-ofkin for deceased respondents was conducted in 2003. A third wave of interviews is currently under preparation. MHAS oversampled the six Mexican states from which 40 per cent of all migrants to the United States originate. The survey includes information on the same core content as the HRS and migration history to the United States.

\section{English Longitudinal Study of Ageing (ELSA)}

ELSA is a longitudinal survey of more than 12,000 community-residing English men and women representing the population aged 50 or older. ${ }^{4}$ The sample design differs from that for the HRS, with a baseline sample of 11,400 persons born before 1 March, 1952, drawn from respondents to a prior survey, the Health Survey for England. As a result, fairly rich data are already available at baseline. A refreshment sample of persons aged 50 to 54 was recruited at the third wave, and a boost sample comprising a cross-section of persons aged 50 to 74 was added in the fourth wave. ELSA covers the same topics as the HRS with additional questions on health symptoms and psycho-social characteristics. It has started collecting biological markers and retrospective life-history data using a computerized

\footnotetext{
${ }^{3}$ See $<$ http://www.mhas.pop.upenn.edu/english/home.htm>.

${ }^{4}$ See $<$ http://www.ifs.org.uk/elsa/index.php>.
} 
calendar method. ELSA provides a linkage to administrative data, including that on mortality, cancer registration, hospitalization, national insurance records (i.e. social security contributions), benefits and tax credits.

\section{Survey of Health, Ageing, and Retirement in Europe (SHARE)}

SHARE is a European multidisciplinary and cross-national panel interview survey on health, socio-economic status, and social and family networks of individuals who are at least aged $50 .^{5}$ Its baseline wave in 2004 interviewed more than 22,000 community-residing Europeans in eleven countries - Denmark, Sweden, Austria, France, Germany, Switzerland, Belgium, the Netherlands, Spain, Italy and Greece - representing all regions of Europe. A second wave of data collection took place in these countries in 2006. Other countries have since joined SHARE. In 2006, the Czech Republic, Poland and Ireland had their first wave of data collection. The third wave of SHARE, completed in 2008-2009, included retrospective lifehistory interviews with about 30,000 individuals from these 14 European countries. SHARE also collected data for Israel in 2005-2006 and for Slovenia in 2008-2009. Modelled after HRS and ELSA, the SHARE interviews both respondents and spouses, covering the same topics but asking fewer questions. A common questionnaire was developed in English and then translated into local languages to optimize comparability of the data collected. In some domains where institutions are important, modules of the questionnaire differ across countries but still aim to collect conceptually comparable data. SHARE plans to collect biomarker data. The average household response rate in the first assessment was 62 per cent, ranging from 39 per cent (Switzerland) to 81 per cent (France). Although lower than in HRS, response rates are higher or comparable to those in previous European surveys.

\section{Korean Longitudinal Study of Ageing (KLoSA)}

KLoSA is a nationally-representative panel survey of more than 10,000 community-residing citizens aged 45 or older in the Republic of Korea (hereafter, South Korea). ${ }^{6}$ KLoSA uses a lower age cut-off, reflecting the earlier transition to retirement in South Korea (Lee, 2007b). This age cut-off has been adopted for surveys in the People's Republic of China (hereafter, China) and India, where the informal sector of employment is relatively large. The baseline survey instrument has the same core contents as the HRS. On account of the fact that many older adults in South Korea co-reside with their children or other family members, KLoSA interviews all age-qualifying individuals in a household, rather than choosing only one respondent (and spouse). Consequently, non-age qualifying spouses are not interviewed until they reach the target age of 45; once they do, they are interviewed. Given that family transfers play a key role in old-age income security in South Korea, KLoSA includes questions on the regularity, type, and reciprocity of such transfers (questions that were later adopted by the CHARLS in China). KLoSA collected baseline data through face-to-face interviews in 2006, and a second wave of data in 2008. KLoSA collected work-history data in 2007, using the computerized calendar method similar to the ELSA life-history interview.

\footnotetext{
${ }^{5}$ See $<$ http://www.share-project.org $>$.

${ }^{6}$ See <http://www.kli.re.kr/klosa/en/about/introduce.jsp>.
} 


\section{Japanese Study on Aging and Retirement (J-STAR)}

J-STAR is a multidisciplinary panel study of community-residing older Japanese adults. The baseline sample includes more than 4,200 Japanese aged 50 to 75. J-STAR was designed to capture the same key concepts of HRS, and particularly those similar to SHARE. J-STAR added a self-completion questionnaire to collect data on food intake. J-STAR's sampling design is distinct from that of the others in the HRS family of surveys: it represents selected municipalities rather than the national population. It was chosen to examine the effects of policy differences across municipalities; the municipalities were chosen for granting access to administrative data and good representation across different regions of the country. The first wave, conducted in 2007, used a stratified random sample of five municipalities with linkage to health expenditure records. The J-STAR research team has added two municipalities for its second wave that is currently in the field. The team plans to increase the number of municipalities in the survey to ultimately obtain a nationally-representative sample. The response rate for the 2007 study was 59 per cent, which is relatively high for Japanese surveys but relatively low for the HRS family of surveys generally.

\section{Chinese Health and Retirement Longitudinal Study (CHARLS)}

CHARLS is a biennial survey undertaken in ten provinces of the People's Republic of China that aims to represent the residents of China that are aged 45 or older. ${ }^{7}$ The pilot survey of about 1,500 households took place in 2008 in two provinces: Zhejiang, located in the developed coastal region, and Gansu, located in the less-developed western region. With a structure and contents closely modelled on the KLoSA, CHARLS interviews respondents who are at least aged 45 and their spouses. Unique features of CHARLS include a consumption module and a community survey that was modelled after the Indonesian Family Life Survey (see annex), including information about village land policy, infrastructure and utilities, out-migration, health facilities, health insurance, community wage levels, facilities for the elderly, history of policy change, natural disasters or epidemics, price levels, and other statistics such as population, in-migration, and finance. The CHARLS team plans a national baseline survey in ten provinces in 2011 of 12,000 respondents from 7,500 households, including follow-up interviews in the two pilot provinces. The CHARLS team has collected documentation on local social and economic conditions, pension policy, health care and health insurance, and other social welfare policies. It plans to use this information to analyze state-level policy variations and how they are related to health and retirement behaviour.

\section{Irish Longitudinal study on Ageing (TILDA)}

TILDA is a multidisciplinary, longitudinal survey of a nationally-representative sample of 8,000 to 10,000 persons aged 50 or older in Ireland. ${ }^{8}, 9$ The TILDA instrument is modelled on the HRS, but has more comprehensive health assessments, including detailed assessment of cognition and mood, sensory functioning, phasic blood pressure, heart rate variability,

\footnotetext{
${ }^{7}$ See $<$ http://charls.ccer.edu.cn/charls/>.

${ }^{8}$ See <http://www.tcd.ie/tilda/about/project-description/>.

${ }^{9}$ Ireland is also represented in SHARE, but TILDA aims to collect more detailed information about health through direct health assessment at the Health Centers.
} 
pulse wave velocity, functional tests of gait and timed up-and-go, vision, hearing, urine sample, blood sample, and medication. These health assessments are made at health centres because of testing requirements, including equipment needs, while the Computer-Assisted Personal Interview (CAPI) is conducted at respondents' residences. Two pilot studies were conducted in 2008 and 2009. The first wave is currently being fielded; the second wave is planned in two years.

\section{Longitudinal Ageing Study in India (LASI)}

LASI is a multidisciplinary, internationally-harmonized panel survey representing the elderly population in India. ${ }^{10}$ A full-scale, biennial survey of 30,000 Indians aged 45 or older is planned, following the current pilot study. The survey instrument includes the same core contents as the HRS. The LASI team conducted careful pre-tests to capture the institutions and local cultures of India. Other innovations of the LASI include collecting data on physical environment and new questions on health utilization behaviours, ranging from hospitalization to traditional healers, as well as new methods to measure social connections and expectations. The pilot study sample of about 1,500 persons is drawn from four states (Karnataka, Kerala, Punjab, and Rajasthan) using the 2001 Census Primary Census Abstract. Full-scale surveys are planned for 2012 and 2014.

\section{Key parameters of pension and health data}

The HRS family of surveys capture the same key core contents: demographics, family, health conditions and status, work, retirement, pensions, economic status, and social network. ${ }^{11}$ This section discusses the key parameters of pensions and health.

\section{Pensions}

All the surveys collect information on pension plans for any job that a respondent holds at the time of interview as well as for pensions, both private and public, that respondents receive. This allows researchers to estimate pension wealth and to predict future income from pensions. By doing so, researchers can analyze the effect of pension plan provision on retirement decisions and the relative contribution of pension plans to economic security in old age. As a result of institutional differences, specific questions on pension plans differ across the surveys, but all surveys capture both public and private pensions and the characteristics of pension entitlements and pensions income.

HRS-The survey in the Unite States collects descriptive data on all pension plans for any current job the respondent holds, pension plans for the most-recent employer for a respondent not currently working, and pension plans for previous jobs held by respondents. The HRS is also linked to the administrative files of the United States' Social Security Administration (SSA). ${ }^{12}$ Data derived from SSA records and currently available for HRS research are of four types: earnings histories, "Social Security" benefit histories,

\footnotetext{
${ }_{11}^{10}$ See <http://www.hsph.harvard.edu/pgda/lasi.html>.

${ }^{11}$ See Lee (2007a), for the summary of key concepts captured in each domain, and the RAND Mega Meta Data website, <https:// mmicdata.rand.org/wiki/index.php/Main_Page>, for survey questions and additional comparability information across the surveys.

${ }^{12}$ See Mitchell, Olsen, and Steinmeier (1996), for detailed information on linkages with SSA data, and Olsen (1999), for construction of the earnings and benefits data files.
} 
"Supplemental Security Income" payment histories, and prospective "Social Security" wealth measures for respondents and deceased spouses. All HRS data derived from SSA records are available for research purposes under restricted conditions. ${ }^{13}$

HRS asks about the characteristics of defined benefit (DB) and defined contribution (DC) private-pension plans and information on early retirement possibilities and incentives. Periodically, the HRS obtains pension Summary Plan Descriptions (SPDs) from the employers of respondents included in pension plans. These SPDs are then analyzed and coded. The plan and the plan description data, along with specific data (work and income histories) from the respondents are analyzed to estimate the pension entitlements held by respondents (see Stolyarova, Nolte and Peticolas, 2008). There are differences between selfreported information and that derived from the SPDs, particularly for DB plans and for workers who have limited education, earned low wages, and do not expect to retire early (Johnson, Sambamoorthi and Crystal, 2000). Such differences are of interest to research on financial education and the public perception of pension policy.

MHAS-In Mexico, respondents were asked only a few questions about pension contributions and entitlements, but detailed questions about current and expected pension income. Specifically, it asked whether respondents made contributions to a retirement pension or had pension entitlements through their main job, but did not ask the amount contributed. For current and expected pension income, a series of questions identified the type of pension (retirement, survivor, disability, or other), its sources (public or private pension, United States' Social Security Administration, other institution, personal, or other), when respondents started or expected to start receiving pension income, the amount of pension income, and whether a spouse has any entitlement after the respondent dies.

ELSA-The survey in England also asks respondents for details about occupational and personal pension contributions or income. From the second wave onwards, ELSA asks about expectations of future income from state pensions and private pensions. In the third wave, it had questions on the receipt of pension forecast statements. From the third wave onwards, women younger than age 60 were asked about their awareness of changes to the state pension.

As a result of a change in the United Kingdom's state pension age for women having occurred after ELSA began to monitor retirement behaviour, researchers are able to examine the effect of policy change on retirement behaviour. And because the change occurred only for women, researchers, by investigating differences in retirement behaviour for men and women, can investigate how the policy change affected retirement decisions independent of other determinants.

ELSA enables researchers to determine individual pension contributions and pension rights for those not currently drawing pensions and how these might change with employment or retirement decisions. ELSA provides pension wealth variables for each individual, estimating the discounted present value of income that an individual will receive from

${ }^{13}$ See <http://hrsonline.isr.umich.edu/index.php?p=reslis>. 
pensions from the time they are first drawn until death, under various scenarios. This estimation is based on individuals' past and current employment and earnings, as well as on various assumptions about past and future behaviour (e.g. expected retirement) and market conditions (e.g. real return on assets). More information on the derivation of these variables is available in Banks, Emmerson and Tetlow (2005).

SHARE-The European survey asks respondents about current entitlements, contributions to pension plans, the expected age to start receiving a pension, and current pension income from public and private sources, both occupational and personal. It differentiates types of pension incomes, such as old-age, disability, and survivor pensions, and further identifies early retirement or pre-retirement pensions. SHARE also asked whether pension payments were paid as annuities or as a lump-sum, and whether the contributions paid to pension plans were compulsory or voluntary. Given institutional differences across countries, it derives country-specific data. ${ }^{14}$ For example, Swedish researchers developed a list of pensions specific to the country, differentiating occupational pensions for private-sector blue-collar and white-collar workers, municipal and local government workers, and other occupational pension benefits. Despite such institutional differences, core characteristics of pensions, such as the type of pension (i.e. old-age, disability or survivors), its link to previous earnings, the amount of pension income, and future entitlement, are captured for all countries.

KLoSA-The survey in South Korea collects detailed information on public and private pension schemes. This allows researchers to estimate pension entitlement for those not currently drawing a pension and income for those who are. The public National Pension Scheme (NPS) in South Korea was implemented in 1988 and coverage was extended to all workers in 2001, which has contributed to the fact that only 17 per cent of age-eligible respondents were recipients in 2006. Using the benefits formula of the NPS, researchers can estimate public pension income.

The country's occupational pension scheme was reformed in December 2005. Previously, employers with more than five employees were mandated to provide lump-sum "retirement allowances" when employees separated from work regardless of age. On account of the fact that retirement allowances are distributed before actual retirement, pension wealth for those who change jobs may depend on different forms of investments (e.g. savings or home equity) or may have been spent. With the reform, DB and DC plans were introduced for all firms regardless of size. Employers may choose to stay in the retirement allowance system or to establish DB or DC plans, and employers with fewer than 30 employees are allowed to set up individual retirement accounts. This pension policy reform became effective after the first wave of KLoSA, providing researchers with an opportunity to examine the effect of pension reform on retirement and savings behaviours.

J-STAR-In Japan, the survey asks detailed information about current pension income and future pension entitlements. For both current and future pension income, it asks about the

${ }^{14}$ For deviations, see <http://www.share-project.org/_questionnaire/dev2.php? welleid=26>. 
type of pension, including National Pension Plan (basic old-age pension), old-age welfare annuity or retirement mutual pension, survivor's pension, and disability pension; when the pension income started or is expected to start; the amount of pension income; and pension income as a proportion of previous earnings. It asks respondents about knowledge of early and late withdrawal options and whether respondents took advantage of these. It also asks about individual (i.e. personal) pensions from a private insurance company or the postal insurance system.

CHARLS-This survey asks questions on pensions, covering the different pension systems that exist in China, such as the Basic Pension Insurance scheme, commercial pension insurance, government employee pension programmes, and the combined social pooling pension and personal accounts system. It also asks whether current employers provide pension insurance and questions about current pension income, entitlements, and contributions. These questions differentiate the type of pension, sources (i.e. government, previous work unit, social insurance agency, or other entity), and amounts. For the supplemental enterprise pension, it asks whether the plan is DB or DC. For commercial pensions, it asks about the contributions made and the withdrawal options (i.e. lump-sum payment or annuities). Finally, it asks the earliest age respondents can start receiving the pension and if there are any penalties for the early withdrawal of the pension.

LASI-The survey in India asks detailed questions on pension entitlements, income, and contributions. It captures pension schemes through current and past employers, commercial pensions, and government pension schemes for widows, agricultural workers, and the disabled or the elderly. For retirees, questions include the amount of pension income, its replacement rate compared to pre-retirement salaries, the sponsoring employer, and the characteristics of the previous work (e.g. type of work, salary) and retirement (i.e. early, mandatory, official or unofficial). Commercial pension schemes include pension schemes from commercial sources such as the Life Insurance Corporation, the Unit Trust of India or mutual funds. Respondents are asked the amount of their contributions to the scheme and of the benefits (to be) received. The survey also asks respondents about the providers of their pension schemes, that is, whether they are government, institutions, NGOs, cooperative societies, firms, trade union/welfare board (e.g. fishermen, construction, self-employed women), or a commercial insurance company. Those with government pension schemes are asked how long it took to obtain their pension benefits from the date of submitting the application and whether they paid bribes to facilitate the process.

\section{Health}

The HRS family of surveys have greater comparability for health questions. All surveys collect information about health, health insurance, and health care utilization. The surveys collect i) physical health information by asking questions, ii) functional health information by asking questions as well as using performance measures, iii) mental health information by assessing cognitive functioning and asking questions regarding emotional health, iv) direct assessment of biological markers, and v) health insurance affiliation and health care utilization by asking questions and through links to administrative records. 
Self-reported physical health-HRS surveys ask for four types of health information. First, they ask respondents to evaluate their overall health status. Second, they ask questions on chronic diseases and other health problems. Respondents reporting such a diagnosis are asked when they were first diagnosed, whether they are taking medical treatment, and, in follow-up interviews, whether the condition has worsened. Third, they ask about falls and other injuries prevalent among the elderly. CHARLS and KLoSA also ask about traffic accidents and natural disasters. Finally, all HRS surveys ask questions on sensory impairment, pain, symptoms, dental health, and other health conditions.

To overcome the subjective bias of self-reported health measures, HRS, ELSA, SHARE, and LASI included anchoring vignette questions that describe the health status of hypothetical persons and ask respondents to evaluate the health of those persons using the same scale that they used to describe their own health. The use of vignettes helps account for reporting biases in self-reported measures. Their adoption has facilitated cross-country and within-country cross-cultural comparisons of self-reported health. Vignettes have been applied successfully in recent work on international comparisons of health and work disability (Banks et al., 2005; Kapteyn, Smith and Van Soest, 2007).

Functional health-All HRS surveys contain questions about functional health, including activities of daily living (ADL), instrumental activities of daily living (IADL), and mobility questions. For those who have difficulties with ADL and IADL, all HRS surveys collect information about informal care that family members or others provide, as well as about any help with daily activities respondents give to their families and friends.

All HRS surveys also have a series of performance-based measures, such as timed walk, grip strength, chair stands and balance tests. Performance-based measures tap different, complementary constructs of physical functioning than that collected by self-reports of functional health (Suthers and Seeman, 2004).

Mental health-All HRS surveys ask questions about symptoms of depression, but the scale for these varies by survey. HRS, ELSA, KLoSA, and LASI use some form of the Center for Epidemiological Studies-Depression Scale developed by the United States' National Institute of Mental Health. SHARE collects information for constructing the EuroD scale, while MHAS did not include questions on depression.

All HRS surveys include questions to assess cognitive functioning, but cross-country comparability varies. The only common questions across all surveys are on basic cognition, such as questions on naming (objects, presidents/prime minister) and dates. HRS and ELSA collect the most extensive data, including questions on word recall and serial "sevens" (i.e. starting from 100, subtracting the number seven consecutively), measures of numeric ability and vocabulary, and self-rated memory. Each also includes additional questions (backward counting in HRS and prospective memory and letter cancellation in ELSA). Other HRS surveys have only limited questions on cognitive function. KLoSA, CHARLS, and LASI use the Mini-Mental State Examination (MMSE), an 11-question measure screening cognitive impairment (Folstein et al., 1975). Finally, HRS, ELSA, and LASI include a separate proxy cognition interview that consists of overall evaluation of cognitive decline, a short form of 
the Jorm Informant Questionnaire on Cognitive Decline in the Elderly (Jorm, 1994), and questions on behavioural problems.

Biomarkers-The value of biomarkers is widely accepted i) to capture health data from a portion of the population that otherwise would not have such information recorded, ii) for the investigation of molecular determinants in common health outcomes, and iii) to study interactions with social conditions that may subsequently lead to declines in health outcomes. Since the National Research Council's (2001) recommendation that biomarkers be incorporated in social surveys, an increasing number of population surveys, including the HRS family of surveys, have introduced biomarker collection into their survey protocol. The inclusion of biomarkers is particularly important for less-developed countries, where access to health care is more limited and undiagnosed diseases, therefore, more likely than in developed countries. The increasing use of biomarkers has also generated substantial discussions on the ethical issues surrounding their collection, storage, and usage, contributing to strict guidelines for human subjects research (see Wolf and Lo, 2004).

ELSA, as noted, pioneered the collection of biological markers, followed by HRS and more recently by CHARLS, TILDA, and LASI. Although surveys seek common biological markers, the specimen used and the protocols followed differ. ELSA sends nurses to respondents' residences to draw venous blood and saliva samples. HRS sends interviewers to respondents' residences to collect dried blood and saliva samples. TILDA brings respondents to a health examination site to collect venous blood samples. Most of the HRS family of surveys, excepting KLoSA and J-STAR, collect physiological biomarkers, including height, weight, waist circumference, blood pressure, pulse rate, and peak expiratory flow. For molecular biomarkers, all surveys collecting either whole blood or dried blood samples provide measures of cholesterol, C-reactive protein, and glycosylated hemoglobin. HRS is scheduled to genotype its DNA samples and to release genetic data to the scientific community in 2011. ELSA has already genotyped some candidate genes and plans to genotype other candidate genes.

Health insurance and health care utilization-All HRS surveys ask about public and private health insurance, out-of-pocket medical expenses, and health care utilization, including hospitalization, visits to medical general practitioners, preventative care, medication, dental care, and long-term care. This provides researchers with an opportunity to evaluate policy effects on health care utilization. One exemplary study is the HRS Prescription Drug Study. In anticipation of the prescription drug benefit delivered through Medicare Part D in the United States, the HRS team carried out a two-wave companion mail survey designed to track changes in prescription drug utilization. The baseline wave, administered in 2005, was intended to capture prescription drug use, coverage, and satisfaction prior to the implementation of Medicare Part D, as well as awareness of the new drug benefit and available subsidies. The second wave, in 2007, captured similar information post-implementation. As health policy reforms continue all around the world, the needs to evaluate such reforms continue. Two noteworthy reforms warranting analysis through such surveys include the 2010 health care reform in the United States and an anticipated reform of long-term care insurance in South Korea. 


\section{Opportunities for cross-country studies for policy building}

Most developed countries and an increasing number of developing countries regularly survey a large-scale, representative sample of their population to document and monitor key outcome measures of interest such as labour force participation and disease prevalence. Repeated observations from population surveys allow researchers and policy-makers to monitor changes in these measures over time.

Changes in outcome measures are frequently used as evidence for the effectiveness of policy reform. Yet other macro changes can also contribute to changes in outcome measures, so that even with repeated observations, researchers cannot separate the effect of policy changes from that of other changes and cannot therefore gauge policy effectiveness. To estimate how changes in policy affect an outcome of interest, one might conduct an experiment in which participants are randomly assigned to one policy or another. Such an experiment would allow researchers to examine the effects of policy differences that are outside the control of the persons being studied. Yet carrying out such an experimental study in real life would be difficult or impossible. Alternatively, pooling data from multiple countries creates an opportunity to study the effects of policy changes in a natural experimental setting, as policy differences across countries are also outside the control of individuals.

The value of cross-country comparisons is well recognized by the scientific community. For example, Gruber and Wise (1999, 2004, 2007) have conducted a series of cross-country research projects, examining and demonstrating how retirement policy influences the labour market behaviour of older workers. Specifically, they brought together a team of investigators from twelve countries, conducting a set of parallel studies using a common estimation method. They compared the results of each country study to illuminate the policy effect on the timing of retirement $(1999,2004)$ and its fiscal implications (2007). Each country team performed within-country analyses. Cross-country comparisons were then made without pooling data, because micro-data from these countries are not comparable.

Such cross-country comparison of un-pooled data implicitly assumes that the policy effect is the same for all, even though it may depend on individual characteristics. Examining aggregate measures, which reflect only averaged effects, does not provide insight on differential effects across subpopulations. Kapteyn (2010) illustrates the power of pooled cross-country comparisons. Only with comparable micro-data from multiple countries can one analyze whether differences in outcome measures across countries are the result of policy differences. As discussed earlier, an increasing number of countries have started to provide large-scale panel data to track changes in key outcome measures. By exploiting cross-country and over-time variations, one can examine cross-country inter-temporal variations in outcome measures and what contributes to them.

For example, Table 2 compares the changes in observed retirement behaviour and official retirement age across countries and over time. The actual retirement age is below the official retirement age for some countries, but in Japan, South Korea, and Mexico, it exceeds the official age by more than five years. The actual retirement age varies more than official 
retirement ages across countries and is increasing in many countries, especially for women. Despite well-documented cross-country differences in retirement behaviour, our understanding of what contributes to such difference is still limited. Through the use of harmonized and comparable micro-data, researchers can now examine such cross-country differences in changes in retirement behaviour and investigate how policy differences, in official retirement age and in other retirement incentives, contribute to changes in retirement behaviour. Early and normal eligibility ages in public pension systems are examples of cross-country variation in retirement incentives. An example of variation across cohorts within a country stems from legislated changes in early and normal retirement ages, where adjacent cohorts face different retirement ages. Such policy changes can also have differing effects on individuals with different characteristics. By pooling micro-data on individual characteristics with time-specific, country-level policy parameters, researchers can investigate such potential interaction effects.

Tremendous cross-country differences also exist in other key outcome parameters. For example, work disability is increasing in many developed countries. Table 3 shows crosscountry variations in the proportion of workers receiving disability benefits, ranging from 3.2 per cent in Italy to 10.8 per cent in Sweden in 2007 (OECD, 2010). In some countries, disability recipient rates far exceed unemployment rates and impose significant financial burdens. Cross-country variations in disability recipient rates have been explained by policy differences in eligibility rules and the generosity of benefits (Burkhauser and Daly, 2002). Using recent comparable micro-data, Kapteyn, Smith, and van Soest (2007) find another contributor to cross-country variations: differing thresholds for what are work-limiting health conditions across countries and across individuals within countries, and resulting differences in self-reported work disability. As shown in Table 3, the proportions of disability benefit recipients have changed over time across countries; investigating what contributes to such changes is an important research question with significant policy relevance.

The United States is on the verge of a historic shift toward universal health care. Whether and how increased access to care will improve the health of Americans and reduce disparities is of great interest. There are significant cross-country variations in access to health care. These stem from the availability of universal health care and from levels of public insurance coverage. Among countries with universal health insurance, there is great variation in the extent of coverage by public health insurance, ranging from 91 per cent in Luxembourg to 55 per cent in South Korea (OECD, 2009a). Such variation in public insurance coverage results in variations in household out-of-pocket expenditure for health care. Table 4 presents public health insurance coverage and co-payment requirements by country.

To the extent that health care costs are not covered by public health insurance and copayments are required, individual economic resources will affect access to health care. Copayment levels are tied to income in some countries, which may minimize disparities in access, and access to health care varies within countries according to whether private health insurance has been purchased and to economic resources. By pooling individual-level micro-data with time-specific, country-level data on health care systems, research can 
examine the potential interaction effects between individual-level characteristics (the purchase of private insurance and economic resources) and country-level health care system characteristics on health outcomes.

\section{Conclusions}

The value of comparative analysis has been widely recognized. Comparable micro-data across countries and over time enable scientists to investigate the effectiveness of a policy on key outcome measures not only at an aggregate level but also across sub-populations. The scientific promises of such comparative research have not been fully realized because of the lack of comparable micro-data across countries, but this is changing.

An increasing number of countries now provide comparable micro-data, following the lead of the Health and Retirement Study. The HRS family of surveys shares a common research design and collects comparable micro-data with a common goal to better understand the multifaceted lives of older individuals and their families and to track and identify changes over time. As the longitudinal data from harmonized HRS surveys accumulate, their scientific value will grow with the research opportunity to examine longitudinal changes in health and labour force behaviour and the dynamics between the two.

Armed with knowledge about causal relationships, researchers can also use longitudinal, cross-country data to simulate what might happen under different policy scenarios. As policy reforms continue, researchers can use panel data to identify how the adoption of a policy reform launched in one country might be applied in another country, and the implications of such policies for labour force behaviours and health outcomes.

Yet while the development and sharing of micro-data across countries can inform the design of evidence-based policy, it is not sufficient for policy development. The politics of negotiating and implementing policy reform will remain challenging. Nevertheless, as oldage pension policy and health care policy receive more attention, the opportunities for objective analysis that these surveys afford will become even more critical.

\section{Annex}

There are four additional, related surveys worth noting for ageing populations. These are the Indonesian Family Life Survey (IFLS), the WHO Study on Global AGEing and Adult Health (SAGE), the Costa Rican Longevity and Healthy Aging Study (Costa Rica Estudio de Longevidad y Envejecimiento Saludable - CRELES), and the Canadian Longitudinal Study of Aging (CLSA).

\section{Indonesian Family Life Survey (IFLS)}

IFLS is a multidisciplinary, longitudinal survey of 7,244 households representing 83 per cent of the Indonesian population living in 13 of the nation's 27 provinces. ${ }^{15}$ IFLS, first conducted in 1993, was designed as a household survey with interviews of individuals aged 26 or older. The first wave of IFLS interviewed 16,300 respondents from 7,200 households

\footnotetext{
${ }^{15}$ See <http://www.rand.org/labor/FLS/IFLS/>.
} 
randomly drawn from 321 communities in 13 provinces. For its fourth wave in 2007-2008, IFLS was redesigned to collect data on health and retirement comparable to those in the HRS family of surveys. The fourth wave of the IFLS includes questions on retirement and pensions, religiosity, risk preference, time preference, expectations, mental health measures, doctors' diagnoses of chronic conditions, pain, health vignettes, cognition (ten-word recalls), cholesterol, grip strength, and dried blood spots. Among households remaining from the 1993 survey, 91.5 per cent completed the fourth wave, resulting in interviews of 43,500 respondents from 13,500 households. The IFLS community questionnaire (later adopted by CHARLS in China) gathers information about population, land, local industries, weather, natural disasters, and detailed prices from markets. In the fourth wave, the community questionnaire collected additional information about the decentralization of social services, local governance, and community cultural rules. IFLS also gathered information on a list of health facilities that household respondents provided.

\section{Study on Global AGEing and Adult Health (SAGE)}

SAGE was developed by the WHO Multi-Country Studies unit as part of a Longitudinal Survey Programme to compile comprehensive longitudinal information on the health and well-being of adult populations and the ageing process. ${ }^{16}$ The core SAGE collects data on respondents aged 18 or older, with an emphasis on populations aged 50 or older, from nationally-representative samples in six countries (China, Ghana, India, Mexico, the Russian Federation, and South Africa). A baseline cohort was created from the 2002-2004 wave of the World Health Survey (WHS) and contains data on 65,964 adults aged 18 or older, including more than 20,000 persons aged 50 or older. The study protocol includes data collection on income, expenditures and transfers; work history; self-reported assessments of health linked to anchoring vignettes; health care utilization; measured performance tests on a range of different domains of health; well-being, happiness and quality of life; and biomarkers. The SAGE questionnaire was then piloted in 2005 among 1,500 respondents in Ghana, India, and the United Republic of Tanzania. Implementation of the full SAGE was from 2007 to 2009 in six countries. Researchers in each country seek to sample 5,000 households with at least one person aged 50 or older and 1,000 households with a respondent aged from 18 to 49 years. In the older households, all persons aged 50 or older (including spouses and siblings) were invited to participate. In China, a sample was drawn from an existing national surveillance system; in India, a representative sample of six states was included. The follow-up wave is planned for 2010 and 2011.

\section{Costa Rican Longevity and Healthy Aging Study (CRELES)}

CRELES is a nationally-representative longitudinal survey of health and life-course experiences of 2,827 Costa Ricans who were at least aged 60 in 2005. ${ }^{17}$ Baseline household interviews were conducted between November 2004 and September 2006, with two-year follow-up interviews. The sample was drawn from the 2000 population census, with an over-sample of the oldest-old (aged 95 or older). All information, measurements and specimens (including $15 \mathrm{cc}$ of venous blood and overnight urine) were collected in

\footnotetext{
${ }^{16}$ See $<$ http://www.who.int/healthinfo/systems/sage/en/index.html>.

${ }^{17}$ See <http://ccp.ucr.ac.cr/creles/>.
} 
participants' households. Among those contacted, 96 per cent participated in the study and 95 per cent gave blood. In about one in four cases a proxy helped complete the 90-minute interview. Through December 2009, three waves of interviews and measurements have been conducted. The companion sample of younger cohorts, born from 1945 to 1955, was introduced in January of 2010 (CRELES-50). The main study objective was to determine the length and quality of life and the factors contributing to this among the elderly of Costa Rica. Survey topics include self-reported physical health, psychological health, living conditions, health behaviours, health-care utilization, social support, and socioeconomic status, as well as information on pension receipts. Objective health indicators include anthropometrics, observed mobility, and biomarkers from fasting blood (i.e. indicators measured after having not eaten for at least 8 hours) and overnight urine collection (yielding measures of cholesterol, glycosylated hemoglobin, C-reactive protein, cortisol, and other components of integrative allostatic load measures).

\section{Canadian Longitudinal Study of Aging (CLSA)}

CLSA is a nationally-representative, multidisciplinary, longitudinal study of 50,000 Canadians between the ages of 45 and $85 .{ }^{18}$ The study will collect information on the changing biological, medical, psychological, social, and economic aspects of respondents' lives. A population-based, stratified random sample of 50,000 Canadians is currently being recruited using Statistics Canada's Canadian Community Health Survey (CCHS) and will be followed for at least 20 years (or until death). All participants will be interviewed on demographic, social, physical/clinical, psychological, economic, and health service utilization aspects of health and ageing. The CLSA's research domains include cognition (e.g. memory, executive function, speed of processing), social function (e.g. social participation, social stress and work/retirement), physical function (e.g. musculoskeletal function), physical environment (e.g. traffic, noise), labour force environment, and indicators of neighbourhood quality. The CLSA plans to obtain data from federal, provincial, and municipal databases on environmental quality (e.g. green space per capita, air and water quality, and climate), and to develop a linkage to health care use databases across Canada. CLSA also plans to conduct additional physical and clinical assessments for 30,000 respondents, collecting biological specimens such as blood and urine at ten sites (Vancouver, Victoria, Calgary, Winnipeg, Toronto/Hamilton, Ottawa, Montreal, Sherbrooke, Halifax and St. John's) across the country. Follow-up interviews will be conducted every three years.

\section{Bibliography}

Banks, J.; Emmerson, C.; Tetlow, G. Estimating pension wealth of ELSA respondents (IFS working paper, No. 05/09). Institute for Fiscal Studies; London: 2005. <http://www.ifs.org.uk/wps/ wp0509.pdf> (accessed on 06.07.2010)

Banks, J., et al. Work disability is a pain in the $\bullet \bullet$, especially in England, the Netherlands, and the United States (RAND working paper, No. 280). RAND Corporation; Santa Monica, CA: 2005. <http://www.rand.org/pubs/working_papers/WR280> (accessed on 06.07.2010)

${ }^{18}$ See <http://www.cihr-irsc.gc.ca/e/22982.html>. 
Boyle, S. The UK healthcare system (Commonwealth Fund's Health Care System Profiles). 2008. <http://www.commonwealthfund.org/usr_doc/UK_Country_Profile_2008.pdf?section=4061> (accessed on 06.07.2010)

Burkhauser RV, Daly MC. U.S. disability policy in a changing environment. Journal of Economic Perspectives. 2002; 16(1)

Casey BH. Learning across borders: Labour market and social policies. International Social Security Review. 2009; 62(4)

Civitas. Background briefing: Healthcare lessons from Denmark. 2002. 〈http://www.civitas. org.uk〉 (accessed on 13.07.2010)

De Grave D, Van Ourti T. The distributional impact of health financing in Europe: A review". The World Economy. 2003; 26(10)

Folstein M, et al. Mini-mental state, a practical method for grading the cognitive state of patients for the clinician". Journal of Psychiatric Research. 1975; 12(3)

Gruber, J.; Wise, D., editors. Social security programs and retirement around the world. University of Chicago; Chicago, IL: 1999.

Gruber, J.; Wise, D., editors. Social security programs and retirement around the world: Microestimation. University of Chicago; Chicago, IL: 2004.

Gruber, J.; Wise, D., editors. Social security programs and retirement around the world: Fiscal implications of reform. University of Chicago; Chicago, IL: 2007.

Hammer E, Österle A. Welfare state policy and informal long-term care giving in Austria: Old gender divisions and new stratification processes among women". Journal of Social Policy. 2003; 32(1)

Helderman J-K, et al. Market-oriented health care reforms and policy learning in the Netherlands". Journal of Health Politics, Policy, and Law. 2005; 30(1/2)

Johnson RW, Sambamoorthi U, Crystal S. Pension wealth at midlife: Comparing self-reports with provider data". Review of Income and Wealth. 2000; 46(1)

Jorm AF. A short form of the Informant Questionnaire on Cognitive Decline in the Elderly (IQCODE): Sociodemographic correlates, reliability, validity, and some norms". Psychological Medicine. 1994; (19)

Kapteyn, A. What can we learn from (and about) global aging? (RAND working paper, No. 741). RAND Corporation; Santa Monica, CA: 2010. <http://www.rand.org/pubs/working_papers/2010/ RAND_WR741.pdf> (accessed on 06.07.2010)

Kapteyn A, Smith JP, van Soest A. Vignettes and self-reports of work disability in the United States and the Netherlands". American Economic Review. 2007; 97(1)

Kinsella, K.; He, W. An aging world: 2008 (International Population Reports). National Institute on Aging, Census Bureau; Washington, DC: 2009. <http://www.census.gov/prod/2009pubs/ p95-09-1.pdf> (accessed on 06.07.2010)

Lee, J. Harmonizing aging surveys and cross-national studies of aging. Washington, DC, National Institute on Aging — National Institutes of Health. 2007a. <http://www.nia.nih.gov/NR/rdonlyres/ AF0997F6-0C16-4A76-96C0-D3780F00E6D4/7338/ESummary.pdf> (accessed on 06.07.2010)

Lee, J. Aging in South Korea: Findings from korean longitudinal study (Conference paper, IUSSP Seminar "Aging in Developing Countries: Building Bridges for Integrated Research Agendas", Santiago, 23-24 April). International Union for the Scientific Study of Population; Paris: 2007b.

Lopez-Casanovas, G.; Planas-Miret, I. Co-payments in the European healthcare system: A Spanish approach (Draft of a conference paper, "Round Table on Utilisation fees imposed to Public Health Care Systems Users in Europe”, Paris, 29 November). 2001. <http://www.upf.edu/pdi/cres/ lopez_casasnovas/_pdf/Copayments.pdf> (accessed on 06.07.2010)

Mitchell, OS.; Olsen, JA.; Steinmeier, T. Construction of the Earnings and Benefits File (EBF) for use with the Health and Retirement Survey (NBER working paper, No. 5707). National Bureau of Economic Research; Cambridge, MA: 1996.

National Research Council. Preparing for an aging world: The case for cross-national research. National Academy Press; Washington, DC: 2001.

OECD. Health at a glance 2009: OECD indicators. Organisation for Economic Co-operation and Development; Paris: 2009a. 
OECD. Society at a glance 2009: OECD indicators. Organisation for Economic Co-operation and Development; Paris: 2009b.

OECD. Pensions at a glance 2009: Retirement-income systems in OECD countries. Organisation for Economic Co-operation and Development; Paris: 2009c.

OECD. The OECD Sickness, Disability and Work project. Paris, Organisation for Economic Cooperation and Development. 2010. <http://www.oecd.org/document/els/disability> (accessed on 06.07.2010)

Olsen, JA. Linkages with data from social security administrative records in the Health and Retirement Study (ORES working paper, No. 84). Social Security Administration — Office of Research, Evaluation, and Statistics; Washington, DC: 1999.

Reichmann G, Sommersguter-Reichmann M. Co-payments in the Austrian social health insurance system: Analysing patient behaviour and patients' views on the effects of co-payments". Health Policy. 2004; 67

Song Y-J. The South Korean healthcare system”. Japan Medical Association Journal. 2009; 52(3)

Stolyarova, H.; Nolte, M.; Peticolas, B. Pension Estimation Program user guide. University of Michigan; Ann Arbor, MI: 2008. <http://hrsonline.isr.umich.edu/sitedocs/pep/ PenCalcUser2008.pdf> (accessed on 06.07.2010)

Suthers, K.; Seeman, T. A procedure for linking psychosocial job characteristics data to health surveys. National Institute on Aging — National Institutes of Health; Washington, DC: 2004.

Willis, R. Aging in the U.S.: Health and retirement study (Conference paper, "Conference on Longitudinal Social Surveys in an International Perspective", Montreal, 25-27 January). 2006. <http://www.ciqss.umontreal.ca/Longit/session2_ paper2.html> (accessed on 06.07.2010)

Wolf LE, Lo B. Untapped potential: IRB guidance for the ethical research use of stored biological materials". IRB. 2004; 26(4) 


\section{Table 1}

Summary of the HRS family of surveys

\begin{tabular}{|c|c|c|c|c|c|c|c|c|c|}
\hline Surveys & HRS & MHAS & ELSA & SHARE & KLoSA & J-STAR & CHARLS & TILDA & LASI \\
\hline Country & United States & Mexico & $\begin{array}{l}\text { United } \\
\text { Kingdom }\end{array}$ & Europe & $\begin{array}{l}\text { Rep. of } \\
\text { Korea }\end{array}$ & Japan & P.R. of China & Ireland & India \\
\hline Enrolment years & $\begin{array}{l}1992,1993, \\
1998, \\
2004,2010\end{array}$ & 2001 & $\begin{array}{l}2002,2006, \\
2008\end{array}$ & $\begin{array}{l}2004,2006 \\
2008\end{array}$ & 2006 & 2007, 2009 & 2008,2011 & $2009 / 2010$ & 2010,2012 \\
\hline Follow-up frequency & Every 2 years & $\begin{array}{l}\text { Follow-up } \\
\text { in } 2003\end{array}$ & $\begin{array}{l}\text { Every } \\
2 \text { years }\end{array}$ & $\begin{array}{l}\text { Every } \\
2 \text { years }\end{array}$ & $\begin{array}{l}\text { Every } \\
2 \text { years }\end{array}$ & $\begin{array}{l}\text { Every } \\
2 \text { years }\end{array}$ & $\begin{array}{l}\text { Follow-up in } \\
2011 \\
\text { then every } 2 \\
\text { years }\end{array}$ & $\begin{array}{l}\text { Every } \\
2 \text { years }\end{array}$ & $\begin{array}{l}\text { Every } \\
2 \text { years }\end{array}$ \\
\hline $\begin{array}{l}\text { Number of waves } \\
\text { available to date }\end{array}$ & 8 & 2 & 3 & 2 & 2 & 1 & 1 & 0 & 0 \\
\hline Sample size & 30,000 & 13,550 & 12,000 & 30,000 & 10,000 & 4,200 & 10,000 & $8,000-10,000$ & 30,000 \\
\hline Age eligibility & $50+$ & $50+$ & $50+$ & $50+$ & $45+$ & $50-75$ & $45+$ & $50+$ & $45+$ \\
\hline Response rate: baseline & $70-81 \%^{1}$ & $90 \%$ & $67 \%^{2}$ & $62 \%$ & $65 \%$ & $60 \%$ & $82 \%$ & NA & NA \\
\hline $\begin{array}{l}\text { Retention rate: latest } \\
\text { wave }\end{array}$ & $88-92 \%^{1}$ & $94 \%$ & $78 \%^{3}$ & $72 \%$ & $87 \%$ & NA & NA & NA & NA \\
\hline
\end{tabular}

Notes:

${ }^{1}$ The response and retention rates in HRS vary across age cohorts.

2

2 The baseline response rate in ELSA is not comparable to the other data sets, because its sampling frame was a pool of respondents who had already participated in the Health Survey for England.

3 The retention rate for the third wave is for the core sample only, not including younger spouses and new partners. 
Table 2

Changes in the average effective and official retirement ages over time across countries

\begin{tabular}{|c|c|c|c|c|c|c|c|c|}
\hline & \multicolumn{4}{|l|}{ 1997-2002 } & \multicolumn{4}{|l|}{$\underline{2002-2007}$} \\
\hline & \multicolumn{2}{|l|}{ Men } & \multicolumn{2}{|l|}{ Women } & \multicolumn{2}{|l|}{$\underline{\text { Men }}$} & \multicolumn{2}{|l|}{ Women } \\
\hline & Effective & Official & Effective & Official & Effective & Official & Effective & Official \\
\hline Australia & 63.2 & 65 & 60.6 & 62 & 64.4 & 65 & 62.2 & 63 \\
\hline Austria & 59.6 & 65 & 58.9 & 60 & 58.9 & 65 & 57.9 & 60 \\
\hline Belgium & 58.5 & 65 & 56.8 & 62 & 59.6 & 65 & 58.3 & 62 \\
\hline Canada & 63.1 & 65 & 61.4 & 65 & 63.3 & 65 & 61.9 & 65 \\
\hline Czech Republic & 62.0 & 61.2 & 58.3 & 59.3 & 62.2 & 62 & 58.5 & 59 \\
\hline Denmark & 65.3 & 67 & 62.1 & 67 & 63.5 & 65 & 61.3 & 65 \\
\hline Finland & 60.8 & 65 & 59.8 & 65 & 60.2 & 65 & 61.0 & 65 \\
\hline France & 59.3 & 60 & 59.4 & 60 & 58.7 & 60 & 59.5 & 60 \\
\hline Germany & 60.9 & 65 & 60.2 & 65 & 62.1 & 65 & 61.0 & 65 \\
\hline Greece & 62.4 & 58 & 60.9 & 58 & 62.4 & 58 & 60.9 & 58 \\
\hline Hungary & 57.8 & 62 & 56.0 & 58 & 59.7 & 62 & 58.2 & 60 \\
\hline Iceland & 69.6 & 67 & 67.8 & 67 & 68.9 & 67 & 65.3 & 67 \\
\hline Ireland & 65.2 & 66 & 66.2 & 66 & 65.6 & 66 & 64.9 & 66 \\
\hline Italy & 61.2 & 65 & 60.5 & 60 & 60.8 & 65 & 60.8 & 60 \\
\hline Japan & 69.6 & 60 & 65.7 & 60 & 69.5 & 63 & 66.5 & 61 \\
\hline Rep. of Korea & 68.0 & 60 & 66.8 & 60 & 71.2 & 60 & 67.9 & 60 \\
\hline Luxembourg & 59.8 & 65 & 59.8 & 65 & 59.2 & 65 & 60.3 & 65 \\
\hline Mexico & 73.8 & 65 & 67.2 & 65 & 73.0 & 65 & 75.0 & 65 \\
\hline Netherlands & 61.0 & 65 & 59.1 & 65 & 61.6 & 65 & 61.3 & 65 \\
\hline New Zealand & 64.3 & 65 & 61.3 & 65 & 66.5 & 65 & 63.9 & 65 \\
\hline Norway & 63.7 & 67 & 62.3 & 67 & 64.2 & 67 & 63.2 & 67 \\
\hline Poland & 60.9 & 65 & 58.8 & 60 & 61.4 & 65 & 57.7 & 60 \\
\hline Portugal & 65.8 & 65 & 63.5 & 65 & 66.6 & 65 & 65.5 & 65 \\
\hline Slovakia & 59.4 & 60 & 56.1 & 55 & 59.3 & 62 & 54.5 & 62 \\
\hline Spain & 61.6 & 65 & 61.3 & 65 & 61.4 & 65 & 63.1 & 65 \\
\hline
\end{tabular}

Int Soc Secur Rev. Author manuscript; available in PMC 2015 July 28. 


\begin{tabular}{|c|c|c|c|c|c|c|c|c|}
\hline & \multicolumn{4}{|l|}{$\underline{1997-2002}$} & \multicolumn{4}{|l|}{$\underline{2002-2007}$} \\
\hline & \multicolumn{2}{|l|}{ Men } & \multicolumn{2}{|l|}{ Women } & \multicolumn{2}{|l|}{ Men } & \multicolumn{2}{|l|}{ Women } \\
\hline & Effective & Official & Effective & Official & Effective & Official & Effective & Official \\
\hline Sweden & 63.5 & 65 & 62.0 & 65 & 65.7 & 65 & 62.9 & 65 \\
\hline Switzerland & 66.6 & 65 & 63.2 & 63 & 65.2 & 65 & 64.1 & 64 \\
\hline Turkey & 62.5 & 60 & 61.9 & 58 & 63.5 & 60 & 64.3 & 58 \\
\hline United Kingdom & 63.1 & 65 & 61.2 & 60 & 63.2 & 65 & 61.9 & 60 \\
\hline United States & 65.0 & 65 & 62.9 & 65 & 64.6 & 65.8 & 63.9 & 65.8 \\
\hline
\end{tabular}

Source: OECD (2009b). 
Table 3

Disability benefit recipients in per cent of the population aged 20-64 across countries over time

\begin{tabular}{|c|c|c|c|c|c|}
\hline Country & First year & $\begin{array}{l}\text { Mid-1990s or earliest } \\
\text { year available }\end{array}$ & $\begin{array}{l}2007 \text { or latest } \\
\text { year available }\end{array}$ & Last year & $\begin{array}{l}\text { Annual } \\
\text { change }\end{array}$ \\
\hline Hungary & 2000 & 12.3 & 12.1 & 2007 & -0.26 \\
\hline Sweden & 1995 & 8.2 & 10.8 & 2007 & 2.32 \\
\hline Norway & 1995 & 7.7 & 10.3 & 2007 & 2.48 \\
\hline Finland & 1995 & 10.0 & 8.5 & 2007 & -1.35 \\
\hline Netherlands & 1999 & 9.4 & 8.3 & 2007 & -1.52 \\
\hline Denmark & 1995 & 7.4 & 7.2 & 2006 & -0.26 \\
\hline Poland & 2004 & 9.2 & 7.2 & 2007 & -7.90 \\
\hline Czech Republic & 1995 & 6.8 & 7.1 & 2007 & 0.34 \\
\hline United Kingdom & 1995 & 7.0 & 7.0 & 2007 & 0.06 \\
\hline Slovakia & 1995 & 6.7 & 6.3 & 2006 & -0.55 \\
\hline Ireland & 2001 & 5.2 & 6.3 & 2007 & 3.25 \\
\hline Belgium & 1996 & 4.8 & 6.0 & 2007 & 2.01 \\
\hline United States & 1995 & 4.7 & 5.9 & 2006 & 2.04 \\
\hline Australia & 1995 & 4.2 & 5.4 & 2007 & 2.14 \\
\hline Switzerland & 1995 & 3.7 & 5.4 & 2007 & 3.28 \\
\hline France & 1995 & 4.0 & 4.9 & 2004 & 2.34 \\
\hline Luxembourg & 1995 & 7.2 & 4.9 & 2005 & -3.86 \\
\hline Portugal & 1995 & 6.5 & 4.7 & 2007 & -2.65 \\
\hline Greece & 2005 & 4.2 & 4.6 & 2007 & 5.44 \\
\hline Austria & 1995 & 4.9 & 4.6 & 2007 & -0.63 \\
\hline Germany & 1995 & 4.2 & 4.4 & 2007 & 0.51 \\
\hline Canada & 1996 & 4.3 & 4.3 & 2007 & 0.02 \\
\hline New Zealand & 1995 & 2.4 & 3.8 & 2007 & 3.83 \\
\hline Spain & 1995 & 3.1 & 3.8 & 2007 & 1.66 \\
\hline Italy & 2000 & 3.2 & 3.2 & 2006 & 0.01 \\
\hline Japan & 2003 & 1.9 & 2.0 & 2006 & 1.90 \\
\hline
\end{tabular}

Int Soc Secur Rev. Author manuscript; available in PMC 2015 July 28. 


\begin{tabular}{llllll}
\hline Country & First year & $\begin{array}{l}\text { Mid-1990s or earliest } \\
\text { year available }\end{array}$ & $\begin{array}{l}\text { 2007 or latest } \\
\text { year available }\end{array}$ & Last year & $\begin{array}{l}\text { Annual } \\
\text { change }\end{array}$ \\
\hline Rep. of Korea & 1995 & 0.1 & 1.5 & 2007 & 27.44 \\
\hline Mexico & 1995 & 0.7 & 0.7 & 2007 & -0.43 \\
\hline
\end{tabular}

Source: OECD (2009c). 
Table 4

Basic primary health insurance coverage of selected functions of care: Share of typical costs covered, 2008-09 ( $100 \%$ indicates no co-payment is required)

\begin{tabular}{llllll}
\hline & $\begin{array}{l}\text { Acute inpatient } \\
\text { care (\%) }\end{array}$ & $\begin{array}{l}\text { Outpatient primary } \\
\text { care \& specialist } \\
\text { contacts }(\%)\end{array}$ & $\begin{array}{l}\text { Pharmaceuticals } \\
(\boldsymbol{\%})\end{array}$ & $\begin{array}{l}\text { Co-payment tied } \\
\text { to income }\end{array}$ & $\begin{array}{l}\text { Access to } \\
\text { managed care }\end{array}$ \\
\hline Austria & $76-99$ & 100 & $76-99$ & Yes & No \\
\hline Belgium & $76-99$ & $76-99$ & $76-99$ & Yes & No \\
\hline Denmark & 100 & 100 & $51-75$ & Yes & Yes \\
\hline France & $76-99$ & $51-75$ & $51-75$ & Yes & No \\
\hline Germany & 100 & $76-99$ & $76-99$ & Yes & No \\
\hline Greece & $76-99$ & $76-99$ & $76-99$ & No & Yes \\
\hline Italy & 100 & $76-99$ & 100 & Yes & No \\
\hline Rep. of Korea & $76-99$ & $51-75$ & $51-75$ & No & Yes \\
\hline Netherlands & 100 & 100 & 100 & No & Yes \\
\hline Spain & 100 & 100 & $76-99$ & No & Yes \\
\hline Sweden & $76-99$ & $76-99$ & $51-75$ & No & Yes \\
\hline United Kingdom & 100 & 100 & 100 & 100 & \\
\hline
\end{tabular}

Sources: OECD (2009a). Additional information about co-payment structures are drawn from: Austria (Reichmann and Sommersguter-Reichmann, 2004; Hammer and Österle, 2003); Belgium (De Grave and Ourti, 2003); Denmark (Civitas, 2002); Republic of Korea (Song, 2009); Netherlands (Helderman et al., 2005); Spain (Lopez-Casanovas and Planas-Miret, 2001); United Kingdom (Boyle, 2008). 